Journal of Social Sciences 8 (1): 61-65, 2012

ISSN 1549-3652

(C) 2012 Science Publications

\title{
Ergonomics Issues in Malaysia
}

\author{
${ }^{1}$ Loo, H.S. and ${ }^{2}$ Stanley Richardson \\ ${ }^{1}$ Centre of Ergonomics, Faculty of Mechanical Engineering, \\ Universiti Teknologi MARA, 40450 Shah Alam, Selangor, Malaysia \\ ${ }^{2}$ Faculty of Management, Multimedia University, \\ 63100 Cyberjaya, Selangor, Malaysia
}

\begin{abstract}
Problem statement: Ergonomics so far has had little impact in Malaysia. For most Malaysian managers, ergonomics is not considered to be associated with performance, but rather with occupational health and safety and legislation. Approach: This study reviews the development of ergonomics in Malaysia and the underlying issues related to national development. Results: Many changes need to be made within the ergonomics research, education and practice community by integrating concepts from the social sciences with technological advances into Malaysian culture to enhance productivity and sustainable improvements in the quality of life, while achieving essential health and safety goals. Conclusion/Recommendation: Ergonomics helps to improve performance besides enhancing workplace OSH. It is essential to promote ergonomics concepts and practice to various industries in Malaysia. More effort and skills are required to compensate for the lack of infrastructure in providing a framework within which ergonomics recommendations can be disseminated and realized.
\end{abstract}

Key words: Developing countries, ergonomics awareness, industrial discomfort

\section{INTRODUCTION}

In August 2000, the International Ergonomics Association (IEA) asserted that "Ergonomics (or human factors) is the scientific discipline concerned with the understanding of interactions among humans and other elements of a system and the profession that applies theory, principles, data and methods to design in order to optimize human well-being and overall system performance" (IEA Council, 2000). Simply, ergonomics seeks to adapt tasks, working conditions, work methods, tools, machines to maximise their suitability for people. It is a way of looking at the overall organization of the design of tasks, tools, equipment, workplace layouts, work methods to fit jobs to the workers, but personal selection is important too. Therefore, ergonomics is all embracing, as long as machines and their users exist. In any well designed work system, health and safety should embody ergonomics principles. An effective application of such principles can achieve a balance between worker characteristics and task demands, enhance productivity and provide workplace safety, physical and mental well being and job satisfaction (Grandjean, 1988; Konz 1984; Sanders and McCormick, 1993). On the other hand, neglect of ergonomics principles brings inefficiency and pain to the operator. An ergonomically deficient workplace can cause physical and emotional stress, low productivity and poor quality of work (Karwowski, 1998). The logic behind ergonomics and its benefits is that ergonomics optimizes the interface of human physical and mental aspects with machines and the environment in developing a conducive working environment. Thus, an ergonomically-designed workplace is less error-prone and more productive than otherwise it might be. Better quality products can be produced and workers will have better Occupational Safety and Health (OSH). A low cost ergonomics investment giving many benefits is cost effective.

The discipline of ergonomics has been regarded as rather new (Sen, 1984; 1998; O'Neill, 2000) in Malaysia, an industrially developing country. Few research studies in this discipline have been made compared to industrially advanced countries. In this study, the growth of ergonomics in Malaysia since its inception is discussed. Results from various related surveys are also discussed, along with some issues highlighted. The aim of this study is to stress the need to address ergonomics problems in Malaysia.

Corresponding Author: Loo, H.S., Centre of Ergonomics, Faculty of Mechanical Engineering, Universiti Teknologi MARA, 40450 Shah Alam, Selangor, Malaysia 


\section{MATERIALS AND METHODS}

Ergonomics developments and research: The use of ergonomics concepts and principles started in Malaysia several decades ago (Fox and Richardson, 1968; Richardson et al., 1972; Sen, 1984; 1998). In terms of ergonomics awareness, most manufacturing and service industries in the country may suffer, as the discipline is either new or unknown.

During the mid 1970s, Malaysia became one of the new Industrially Developing Countries (IDCs). Its economic development changed from agriculturalbased to that of manufacturing. Foreign investors from many developed countries, such as Sony, Siemens, Intel, Motorola, National Semiconductor, Panasonic and Advanced Micro Devices established their manufacturing and assembly plants in the country because of English language comprehension, abundant workforce, cheap labor and a stable political situation. This phenomenon gave the impetus to the growth of local Small and Medium Industries (SMIs) which complement Foreign Direct Investments (FDIs).

Industry: Early industrial workers were those who used to work in the agricultural sector, hence, many of them had to readjust their physiological and psychological capabilities to suit industrial procedures different from their agricultural-based work (Ali et al., 2001). Specific work instructions, tools and work schedules were given and enforced such that activities could be standardized and outputs with uniform quality could be achieved. The importance of industrial OSH requires constant attention in Malaysia: ergonomic implications are discussed in Vijay et al. (2006).

Discomfort at work: Chee and Rampal (2004) investigated the ergonomic risk factors relevant to work-related musculoskeletal problems among 906 women semiconductor workers in Malaysia. They discovered, inter alia, that neck/ shoulder pain was significantly higher for workers with shorter working durations, while lower-limb pain was significantly higher for those with longer working durations. With the same sample, Chee et al. (2004) discovered that “...front of line workers, who mostly walked around to operate machines...had the lowest prevalences of body pain...middle of line workers... who did frequent lifting, had high pain prevalences in the neck/shoulders (54.8\%) and upper back (43.5\%)." Those who had to climb steps to load units had a high prevalence of lower limb pain $(68.0 \%)$.

Two examples of human computer interaction problems in Malaysia are in Sen and Richardson (2004)
Sen and Richardson (2007). The first of these demonstrates cross-cultural differences. The second surveyed the prevalence of Computer Vision Syndrome (CVS) of 136 students and office staff using computers. It was found that many were using equipment without ergonomic modifications and around half the subjects with low back pain had no adjustable backrest on their seats. The increase of CVS scores (suggesting more subjective symptoms) correlated with increase in computer usage spells.

Public payphones redesign: Khong et al. (2010) conducted an ergonomics research to determine the effectiveness and efficiency of icon recognition on public payphones in Malaysia. The study was conducted using surveys and usability testing. A preliminary study was conducted at Multimedia University Cyberjaya campus. A similar approach to include redesigned icons was conducted in Kuala Lumpur, Putrajaya, Selangor, Perak, Penang, Pahang, Johor, Melaka, Negeri Sembilan, Sabah and Sarawak. Participants were requested to describe public payphone icons in less than 5 words and to guess the meaning for icons that they were uncertain. All icons were randomly located and coded. There were 7 icon categories namely, insert card/coin, adjust volume, redial, followon-call, language select, operator assist and emergency. A similar approach was conducted in a public survey using new and redesigned icons in Kuala Lumpur, Putrajaya and several Malaysia states. Significant icon design changes were suggested.

Ergonomic interventions in factories: Loo and Yeow (2007) and Soo (2008) introduced a brazing tool design-twin brazing torch to a real life brazing workstation of an air handler coil assembly plant to produce quality coil assembly, improve productivity and reduce manufacturing cost. The ergonomics intervention implemented also resulted in stress relief as well as reducing Work-related Musculoskeletal Disorder (WMSD) among the brazing operators. Yeow and Loo (2009) employed ergonomics methods to identify industrial risks in an air handler factory in Malaysia. They conducted ergonomics intervention to rectify the risks via the use of twin brazing tools for the brazing process along with the brazing method to reduce WMSDs.

Ergonomics problems and awareness: According to Shameem et al. (2001), industrial workers in Malaysia experienced little work freedom and relaxation and significant overtime work. They did not complain strongly about poor work conditions, such as background stressors i.e., noise, heat stress due to poor 
air conditioning, limited working space and poor vision due to low lighting levels. Most of these workers were poorly educated and were ignorant of the various work environmental standards. These workers had the idea that work conditions were what they had to adapt to. In fact, in the 1980s, most multinational companies in Malaysia had put ergonomics as low priority, as application of the knowledge of ergonomics was perceived as a costly and burdensome expenditure (Yeow and Sen, 2002) rather than a rewarding investment. This was also due to the abundance of replaceable cheap labour and low government regulation of labour health and safety issues. According to Yeow (2003) on the Malaysian OHS regulations, "a lenient fine of up to US $\$ 1,316$ or six months' jail is levied upon the employer who failed to set up an OHS committee. The maximum liable fine to the employer for violation against OHS regulations is only US\$ 13160 or 2 years' jail, or both." Such lax laws do not serve well as a disincentive.

Most Small and Medium Industries (SMI) in Malaysia started with minimum capital. They were production oriented with little or no knowledge of ergonomics principles applicable for instance, to improving work procedures, material handling techniques, tool designs, workstation and teamwork environments to promote OHS, achieve better quality and gain cost benefits. Due to low budget constraints, they couldn't hire anergonomics professional or an industrial engineer to carry out ergonomic improvements in their workplace. Indeed, such specialists were few. Research collaboration between industries and academia in terms of funding contributions from industry is an uphill endeavour in view of the different perspectives. Industries tend to focus on share value and customers. Academic ergonomics researchers, however, focus on new knowledge and discovery of cause-effect connections between machines, human and the environment; they concentrate on basic and applied research.

An industrial survey conducted by Ali et al. (2001) in the Kinta Valley area in Perak state (where mostly the engineers of the companies were interviewed) discovered some interesting findings such as:

- There was confusion between the words "ergonomics" and "economics

- Engineers thought that Ergonomics is only applicable to product design

- None of those interviewees had taken ergonomics or human factors engineering courses during their tertiary education

- They had no knowledge of ergonomics linkages to industrial health and safety
Due to limited education in the field of ergonomics, the level of knowledge and awareness of the discipline among Malaysian engineers and managers is low. Out of many colleges and universities in the country, only a few offer or have offered ergonomics courses, i.e. Universiti Teknologi MARA, Multimedia University, Universiti Putra Malaysia, Universiti Teknologi Malaysia, Universiti Kebangsaan Malaysia, Universiti Malaysia Sabah, Universiti Malaya, Universiti Malaysia Sarawak and Universiti Malaysia Perlis.

In a recent study on ergonomics awareness in Malaysian manufacturing industries by Mustafa et al. (2009), the researchers discovered that:

- $35.6 \%$ of Malaysian manufacturing industries have a high level of ergonomics awareness

- $33.3 \%$ of the manufacturing industries implemented ergonomics programmes

- Among the types of ergonomics programmes implemented, orientation was mostly used (44.4\%) and proves the most effective

- The main factors for the lack of ergonomics awareness were the lack of information/education/training and no pressure from the top management to initiate the ergonomics programmes

From this study, it is not just the poor local educational emphasis but also poor corporate education and training that contribute to the low ergonomics awareness in Malaysia. There have been some efforts to curb these problems such as the establishment of the ergonomics division in the National Institute of Occupational Safety and Health (NIOSH), the founding of the MMU Centre of Excellence for Ergonomics in 1998 and the launching of the Institute of Design and Ergonomics Application by University Malaysia Sarawak (1997). However, such efforts have hardly raised the awareness level in the corporate sectors.

The third Industrial Master Plan (IMP3): Malaysia has a vision to become a developed country by the year 2020. One of the strategies to achieve this is through the implementation of the 3rd Industrial Master Plan (IMP3), unveiled on 18 August 2006. The Government of Malaysia aims to improve and strengthen the competitiveness of three economic pillars of the country (manufacturing, services and agriculture) with the theme: Malaysia-Towards Global Competitiveness. As the seed of ergonomics has been planted, it is imperative that its progress in both education and practice is steadfast via government interventions along with funding contributions. 


\section{RESULTS AND DISCUSSION}

Many ergonomics problems in Malaysia remain unsolved. Most newly developing countries, like Malaysia, are tropical, or sub-tropical. Thus there is little variation in daily exposure to sunlight, in contrast to most developed countries (e.g., in Europe and North America). The effects these differences have on workload and stress have hardly been researched. It would be interesting to investigate the introduction of a siesta in Malaysia, although cynics will say we have it already. It seems that considerable energy at work is expended too little purpose, e.g., in agriculture (Sen et al., 1983). "Assessing the value of work is as important as the measurement of workload" (Singleton, 1990) which underlines the importance of stress at work (Tang, 1986; Richardson et al., 1986). Little research has been done on work stress in Malaysia.

One gap in this study is the ergonomic importance of cross-cultural differences within Malaysia (Sen and Richardson, 2004) and between Malaysia and developed countries, especially regarding machine and tool design. Examples of relevant research outside Malaysia are from Singapore (Richardson et al., 1972) and Hong Kong (Courtney, 1994). The importance of cross-cultural differences in Malaysia has been discussed, for instance, by Fontaine and Richardson (2005). But the topic requires continuing attention.

\section{CONCLUSION}

It is a fact that in developed countries, ergonomics helps to improve productivity and enhance workplace Occupational Safety and Health (OSH). For industrially developing countries such as Malaysia, in which ergonomics is in its infant stage, it is essential to promote ergonomics concepts and practice by disseminating their applications to various industries so that employers and employees become aware of design concepts and work methods that can help to improve workplace conditions and enhance workers' OSH.

Ergonomics in Malaysia is developing at a relatively slow pace. This does little to solve the existing problems in our industries today. It is important to promote appropriate attention and awareness of the benefits of ergonomics by fitting the latter into the culture and strengthening the position of ergonomics and ergonomists in the public and private sectors. In order to realize the desired situation, substantial changes must take place within the ergonomics research, education and practice community by integrating concepts from the social sciences with technological advances to enhance productivity and improve people's health. More effort and skills are required to compensate for the lack of infrastructure in providing a framework within which ergonomists can operate and ergonomics recommendations can be disseminated and realized. It is desirable to trigger more interest in ergonomics research studies and to provide an approach which must be integrated into all national development plans aimed at gathering strength to help maintain the thrust of our national mission, which is to move the national economy up the value chain, from the middle development stage of today to a more productive, value-added, knowledge intensive, more mature and innovative stage by the year 2020 .

\section{ACKNOWLEDGEMENT}

The support of 'e-ScienceFund' from the Ministry of Science, Technology and Innovation (MOSTI) via Research Management Institute (RMI) of Universiti Teknologi MARA (UITM) for funding this research is acknowledged with gratitude.

\section{REFERENCES}

Ali, A.Y., K.C. Chew, M.Z. Razak, 2001. Development of knowledge-based ergonomic software for the small and medium scale industries in Malaysia. Malaysian Ergonomics.

Chee, H.L. and K.G. Rampal, 2004. Work-related musculoskeletal problems among women workers in the semiconductor industry in Peninsular Malaysia. Int. J. Occup. Environ. Health, 10: 6371. PMID: 15070027

Chee, H.L., K.G. Rampal and A. Chandrasakaran, 2004. Ergonomic risk factors of work processes in the semiconductor industry in Peninsular Malaysia. Ind. Health, 42: 373-381. PMID: 15295910

Courtney, A.J.,1994. Hong Kong Chinese direction-ofmotion stereotypes. Ergonomics, 37: 417-426. DOI: $10.1080 / 00140139408963660$

Fontaine, R. and S. Richardson, 2005. Cultural values in Malaysia: Chinese, Malays and Indians compared. Cross Cultural Manage.: Int. J., 12: 6377. DOI: $10.1108 / 13527600510798141$

Fox, J.G. and S. Richardson, 1968. Ergonomics, Engineering and Singapore. 1st Edn., J.G. Fox and S. Richardson, Singapore, pp: 50.

Grandjean, E., 1988. Fitting the Task to the Man: A Textbook of Occupational Ergonomics. 4th Edn., Taylor and Francis, New York, ISBN: 0850663806, pp: 363. 
Karwowski, W., 1998. Ergonomics in Manufacturing: Raising Productivity Through Workplace Improvement. 1st Edn., Society of Manufacturing Engineers, Dearborn, ISBN: 087263485X; pp: 538.

Khong, C.W., CY. Wong and S. Richardson, 2010. Icon designs on public payphones in Malaysia. Design Principles Practices: Int. J., 4: 153-166.

Konz, S.A., 1984. Work Design: Industrial Ergonomics. 2nd Edn., John Wiley and Sons Canada, Limited, New York, ISBN: 9780471841746, pp: 614.

Loo, H.S., P.H.P. Yeow, 2007. Ergonomics intervention in the manufacturing of air handler coil assembly. Proceedings of the International Conference on Ergonomics, Dec. 3-5, Hotel Istana, Kuala Lumpur, Malaysia, pp: 324-328.

Mustafa, S.A., S. Kamaruddin, Z. Othman and M. Mokhtar, 2009. Ergonomics awareness and identifying frequently used ergonomics programs in manufacturing industries using quality function deployment. Am. J. Sci. Res., 3: 51-66.

O’Neill, D.H., 2000. Ergonomics in industrially developing countries: Does its application differ from that in industrially advanced countries? Applied Ergon., 31: 631-640. DOI: 10.1016/S0003-6870(00)00033-8

Richardson, S., H.L. Chan, A. Lee, S.T. Teo, 1972. The Müller-lyer illusion: A cross-cultural study in Singapore. Ergonomics, 15: 293-298. DOI: 10.1080/00140137208924431

Richardson, S., M.L. Wong and S. Pataraparich, 1986. Sex and managerial stress: A Singapore study. Proceedings 23rd Annual Conference of Industrial Ergonomics Society of Australia and New Zealand, Nov. 25-28, Perth, WA., pp: 161-169.

Sanders, M.S. and E.J. McCormick, 1993. Human Factors in Engineering and Design. 7th Edn., McGraw-Hill, New York, ISBN-10: 007054901X, pp: 790 .

Sen, A. and S. Richardson, 2004. Health Problems associated with Prolonged Computer Usage: A CrossCultural Comparison in Malaysia. Proceedings of the 1st International Conference-Seminar on Culture, Dec. 1-5, Sungai Patani, Malaysia.

Sen, A. and S. Richardson, 2007. A study of computerrelated upper limb discomfort and computer vision syndrome. J. Hum. Ergol., 36: 45-50. PMID: 18572794
Sen, R.N., 1984. The Ergonomics Society The Society's Lecture 1983 The Churchill College, Cambridge, England, on 24 March. Ergonomics, 27: 1021-1032. DOI: $10.1080 / 00140138408963583$

Sen, R.N., 1998. Recent trends of ergonomics research in India and Malaysia. HQL Quarterly, 12: 2-4.

Sen, R.N., A.K. Ganguli, G.G. Ray and D. Chakrabarti, 1983. Tea-leaf plucking--workloads and environmental studies. Ergonomics, 26: 887-893. PMID: 6641696

Shameem, S., Z. Taha, I. Nazaruddin, R.A. Ghazilla and N. Yusof, 2001. Perception and attitude of Malaysian industrial workers towards their workplace. Proceedings of the Malaysian Ergonomics 2001: Safe and Healthy Workplaces for Better Productivity and Efficiency, Apr. 17-18, Intel Technology Sdn. Bhd., Penang.

Singleton, W.T., 1990. Workload, Communication and Stress. Ergonomist, 243: 3-3.

Soo, L.H., 2008. Ergonomic improvements in the brazing of air handler coil assembly. Proceedings of the 9th Southeast Asian Ergonomics Society Conference, Oct. 31-31, Bangkok, Thailand.

Tang, E., 1986. Male managers under stress in Singapore. Int. J. Ind. Ergon., 1: 115-126. DOI: 10.1016/0169-8141(86)90015-6

Vijay, V., S. Richardson and R.N. Sen, 2006. Risk perception of structural steel erection workers in Malaysia-Ergonomic implications for occupational safety and health. Proceedings of the ErgoFuture 06 Symposium, Aug. 28-30, Bali, Indonesia, pp: 100-105.

Yeow, P.H.P. and H.S. Loo, 2009. Ergonomics in the brazing operation of an air handler coil factory. Proceedings of the 2nd International Conference on Industrial Risk Engineering, May 13-15th, Reims, France, pp: CIRI043- CIRI043.

Yeow, P.H.P. and R.N. Sen, 2002. The promoters of ergonomics in industrially developing countries, their work and challenges. Proceedings of the 3rd International Cyberspace Conference on Ergonomics, (ICCE' 02), The International Ergonomics, Johannesburg S.A., pp: 18-30.

Yeow, P.H.P., 2003. Ergonomic improvements in the printed circuit assembly factories of the multimedia industry in Malaysia. Multimedia University. 